\title{
Diurnal mouthpiece ventilation and nocturnal non-invasive ventilation versus tracheostomy invasive ventilation in patients with Amyotrophic Lateral Sclerosis
}

Journal: Panminerva Medica

Paper code: Panminerva Med-3644

Submission date: April 7, 2019

Article type: Original Article

Files:

1. Manuscript

Version: 5

Description: manuscript

File format: application/vnd.openxmlformats-officedocument.wordprocessingml.document

2. Figures 1

Version: 1

Description: flow chart

File format: image/tiff

3. Figures 2

Version: 2

Description: figure 2 Kaplan meier diagram

File format: image/jpeg

4. Figures 3

Version: 1

Description: Fig 3a-3b

File format: image/tiff

5. Figures 4

Version: 1

Description: figura 4

File format: image/tiff 
1

\section{Antonello NICOLINI' ${ }^{1}$,Laura PARRINELLO ${ }^{2}$,Bruna GRECCHI ${ }^{2}$,Fulvio BRAIDO ${ }^{3}$,Ilaria BAIARDINI ${ }^{3}$,Corrado} GHIROTTI $^{3}$,Paolo BANFI ${ }^{4}$

1.Respiratory Diseases Unit, General Hospital,Sestri Levante, Italy 2. Physical Medicine and Rehabilitation, General Hospital,Sestri Levante,Italy ${ }^{3}$. Respiratory Diseases and Allergy Clinic, Department of Internal Medicine, University of Genoa, Azienda Policlinico IRCCS San Martino Italy .4. Pulmonary Rehabilitation Unit,Don Gnocchi Foundation IRCCS,Milan, Italy

Corresponding author : Dr Antonello Nicolini,MD Respiratory Diseases Unit General Hospital -16039 Sestri Levante Itaily phone +390185329145 fax +390185329121 e-mail :antonellonicolini@gmail.com

Original Articie Title

Diurnal mouthpiece ventilation and nocturnal non-invasive ventilation versus tracheostomy invasive ventilation in patients with Amyotrophic Lateral Sclerosis 
amyotrophic lateral sclerosis, non nvasive mechanical ventilation, mouthpiece ventilation, tracheostomy mechanical

\section{ABSTRACT}

Background Respiratory disorders are a major cause of morbidity and mortality in Amyotrophic lateral sclerosis (ALS).Current guidelines suggest the provision of noninvasive ventilation (NIV) for symptomatic hypoventilation in patients with ALS. Inspite of these results the proportion of ALS patients on tracheostomy invasive ventilation (TIV) is relatively high.

Methods 32 patients were included in the study: 16 patients were treated with nocturnal NIV associated with diurnal mouthpiece ventilation (MPV) and 16 with TIV. The primary endpoint of the study was to evaluate survival in the two groups. Secondary endpoints were to evaluate differences in the two populations in terms of clinical outcomes and quality of life ( HRQoL).

Results Cox analysis survival data shows no statically difference in the hazard function of the two groups.

The comparison between the two groups showed a significant improvement in the average value of gas indices $\left(\mathrm{paO}_{2}\right.$, $\mathrm{paCO}_{2}$ ) in the group treated with TIV in comparison to the group treated with MPV/NIV. Conversely, the evaluation of the questionnaires on HRQoL showed a higher score in patients treated with M.PVINIV compared to those treated with TIV.

Conclusions Ventilatory treatment with MPV and TIV did not demonstraie significant differences in survival. Patients treated with MPV reported a better HRQoL, although TIV group showed higher ventilatory parameters improvement than MPV group. Ventilation, survival time, respiratory outcomes, quality of life 


\section{Page 3 of 20}

1

2

\section{Introduction}

Amyotrophic Lateral Sclerosis ( ALS ) is a neurodegenerative progressive and multifactorial disease with a poor prognosis, which selectively affects motor neurons, both central and peripheral. The main clinical manifestations consist of generalized asthenia, fasciculations and progressive limitation of all motor activities to cause dysphonia, dysphagia, paralysis and difficulty in breathing ${ }^{1-3}$.

There is evidence that mechanical ventilation (MV) techniques, non-invasive (Nil) or invasive (IMV) improve resistance to stress and ventilatory functions and prolong survival ${ }^{4-8}$; therefore the functional respiratory evaluation is particularly relevant in patients with ALS, above all to optimize their therapeutic-rehabititative program ${ }^{1,9,10}$. NIV proves to be an excellent alternative to IMV ${ }^{11}$ and also a means of weaning from it, even though there are cases in which IMV is the only possible technique in the ALS patient approach because of its performances with regard to respiratory parameters. NIV offers numerovis advantages among which the decreased need for oro-tracheal intubation, associated with side effects such as: upper airway trauma, impaired speech and swallowing and ventilatorassociated pneumonia (with incidence of $30 \%$ and mortality equal to $40-80 \%)^{12}$.

Finally, NIV is less disabling compared to IMV via tracheostomy and allows a wider ability to manage daily activities for the patient and a reduced difficulty of assistance from family members and health personnel, thus reducing rehabilitation costs and improving Health Related Quality of Life (HRQoL) ${ }^{9-14}$. NIV is possibly effective in raising HRQoL for patients with ALS who have respiratory insufficiency ${ }^{15-17}$. Tracheostomy invasive ventilation (TIV) is possibly effective in preserving HRQoL for patients with ALS, but possibly with a greater burden for their caregivers ${ }^{18}$.TIV may be considered to preserve HRQoL in patients with ALS who need long-term ventilatory support ${ }^{18,19}$. 
Page 4 of 20 1

2

The main objective of this observational study was to describe and evaluate the use of daytime NIV using

Mounthpiece ventilation (MPV) in association with conventional nocturnal NIV, compared to TIV in ventilator-

dependent patients affected by ALS; the secondary objectives was to evaluate differences in the two populations in terms of clinical outcomes, and HRQoL.

\section{Material and Methods}

An observational study was carried on at ALS Multidisciplinary Centre and Respiratory Diseases Unit of Hospital of

Sestri Levante,Rehabilitation Pulmonology,Don Gnocchi Foundation,Milan and Pulmonary Department,San Martino Hospital,Genova .This included ALS patients for whom mechangical yentilation was prescribed from January 2014 to December 2018 . Written informed consent was gibtairied from all participarits and procedures were conducted according to the Declaration of Helsinki .The study was approved by each Ethics Commitee ,and registered at Chinese Clinical Trial Registry as ChiCTR1800014772.

\section{Study population and study design?}

All patients were enrolled yith a diagnosis of ALS according to the revised criteria of El Escorial ${ }^{20}$ at the regional Neurological Center of Reference. From the time of their first respiratory evaluation patients were evaluated every two to six months (based on the level of progression of their disease). The tests performed routinely were as follows: Forced Vital Capacity $(F V C)$, Forced Expiratory Volume at the first second $\left(\mathrm{FEV}_{1}\right)$, Maximal Inspiratory Pressure (MIP), Maximal Expiratory Pressure (MEP), Sniff Nasal Inspiratory Pressure (SNIP), Peak expiratory flow after coughing $(\mathrm{PCF})$, arterial blood gas analysis $(\mathrm{ABG})$, oxygen saturation $\left(\mathrm{SatO}_{2}\right)$.Pulmonary function tests were performed with a computerized body plethysmography (VMAX 20 PFT Sensor Medics, Yorba Linda, CA,US), 


\section{Page 5 of 20}

41

according to the ATS/ERS Guidelines ${ }^{21-25}$.HRQoL has been assessed every 6-12 months by mean of SAT- ${ }^{26}$. The SAT-P is a self-administered, generic questionnaire that evaluate daily life satisfaction, a component of subjective HRQoL. It consists of 32 items. The patient is asked to rate his satisfaction by mean of a $10 \mathrm{~cm}$ horizontal visual analogue scale (VAS). The tool provides individual scores about each single item and 5 factor scores, all ranging from 0 (lowest level of satisfaction) to 100 (highest level of satisfaction) ${ }^{27}$.

Moreover, some laboratory parameters were evaluated every three to six months : albumin, pre-albumin,alfa-1 acid glycoprotein and $\mathrm{C}$ reactive protein ( a panel used to evaluate patient's nutritional status $)^{28}$.

NIV was administered when the vital capacity (FVC), fell below $50 \%$ of predicted or clinical signs of nocturnal hypoventilation appeared and / or MIP was found to be below $-60 \mathrm{~cm} H 2 \mathrm{O}$ or $\mathrm{SNMP}$ below $-40 \mathrm{cmH}_{2} \mathrm{O}^{9}$. Cough assistance with physiotherapeutic techniques started if the PCEF had falien below $270 \mathrm{I} / \mathrm{min}$, the Mechanical Cough Assistor (MAC) under $160 \mathrm{l} / \mathrm{m}^{14}$. With the progression the muscle weakness and because of the increasing of use NIV ,MPV was added during the day. The cinicail conditions for starting MPV are reported in table $1^{9}$.

When NIV plus mechanical assisted cough were not atole to mantain an adequate ventilation ( $\mathrm{satO}_{2} \leq 94 \%$ ), TIV has been offered ${ }^{29}$. The yentilator was set in volumetric controlled assisted mode (VCV) during MPV and in pressure ( bilevel -sponianecus/timed-ST or assisted pressure control ventilation -APCV) or volumetric mode (VCV) during the NIV.For these patients a double program provided ventilator was used. Theventilator setting was determined in outpatient clinic. Further adjustments were made based on comfort,symptoms and overnight oximetry or diurnal ABG. Patients with severe bulbar deficiency were treated with TIV .For these patients APCV mode was used. The other patients were treated at the beginning with NIV.Patients who showed deficiency of bulbar fuction during the course of the disease or a suddend and/or severe deterioration were switched to TIV group. The ventilators used were : 
6

deliver MPV.Nasal mask,oronasal mask and full face mask were used to deliver nocturnal NIV following the choice of the patient and the progression of the ventilatory failure.

The patients when it needs underwent percutaneous endoscopy gastrotomy (PEG) for enteral nutrition.

Every patient was provided of airway clearance technique ( cough assistor ) as complementary techniques of mechanical ventilation ${ }^{1}$.Every patient was follow at multidisciplinary clinic team which have enanbled and facilitated the coordination of all procedures, reinforced good practices with early and complete care of their needs. Furthermore, a medical and nursing care care team integrated into the hospital team have taken care for the patients to verify the correct functioning and to ensure correct management of ventilatory treatment by the caregivers.

Demographic data, disease phenotype,age at the time of diagnosis were recorded as they were noted also the beginning of the NIV, the beginning of mechanical ventilation for more than: 12 hours, the beginning of MPV, tracheostomy and death. All tests of respiratory function and quality of life were reviewed by dividing the examination period into 3 phases :

- disease diagnosis phase;

- start of mechanica! ventilation phase;

- last three moniths of life of the patients phase.

\section{Statistical analysis}

For statistical analysis was used the R-Project software version 2.13.2. The results obtained were expressed as mean and standard deviation and evaluated by efferving the $p$-Value (a measure of evidence against the null hypothesis, i.e. the level of significance assigned to that particular value) that was calculated with the Student's test every step. For the comparison between the various parameters of the two different groups, the univariate analysis regression 


\section{Page 7 of 20}

1

2 3

41

test was used. A level of variation greater than 0.05 was statistically significant. Regarding the survival analysis, this was performed using the Kaplan-Maier method; the Log-rank test (Logarithmic Ranks Test) was used to compare the survival of the two groups.To guarantee a blindness for lower risk of bias for clinician-assessed outcomes such as HRQoL the questionnaires were administered by two different nurses and the data were evaluated by an independent statistician blinded to patients' treatment assignment.

\section{Results}

80 patients with ALS were screened in the study; 48 of them were excisdied from the analysis for limited data or for lack of consent to the publication of data or inability to perform respiratory function mieasurements. 32 patients were included in the analysis: 27 patients were initially treated with nocturnal Niv associated with daytime MPV and 5 with TIV.Eleven patients switched to TIV owing to severe dejerioration of bulbar or respiratory function. Finally 16 patients were included into MPV + nocturnal NIV group aind 16 into TIV group ( see study flow chart )( fig.1).

.Baseline characteristics of the patients in the two groups are presented in the table $2 a-2 b$.

The time elapsed from the time of diagnosis to the beginning of the NIV varies from 12 days to 1218 days with an average of 267 da.ys. 22, patients (70\%) had more than one indication for NIV: FVC below $50 \%$ predicted for 21 patients (65\%), followed by 7 patients with MIP less than $-40 \mathrm{cmH}_{2} \mathrm{O}(22 \%)$ and 5 with SNIP less than $-60 \mathrm{cmH}_{2} \mathrm{O}$ (10\%), diurnal hypercapnia for 3 patient (16\%); 2 patients $(6 . \%)$ reported ortopnea and symptoms of respiratory disorders during sleep.The time between the introduction of the NIV and the start of the MPV varies between 20 days to 390 days with an average of 139 days. The MPV was introduced following previously described criteria.Eleven patients, when severe bulbar dysfunction and/or severe respiratory failure happened were switched from MPV/NIV to TIV.Instead, patients who chose not to undergo TIV continued with NIV. In addition, all patients ( with the exception of 
2 patients) underwent PEG for enteral nutrition.

Six patients of the MPV/NIV group were treated with VCV + ST mode,eight patients with VCV + APCV and two with 5

6

VCV .Fourteen patients belonging to TIV group were treated with APCV mode and two with VCV mode.

The average days of ventilatory treatment for each group of patients: 617.56 days for the MPV/NIV

patient group vs 782.69 days for the TIV group. The median days for MPV group were 487 19. No patient died from decision to withdraw mechanical ventilation.Mortality analysis is showed by Kaplan-Maier curves diagram (fig.2).

The Kaplan Meier survival analysis has reported here is a monovariable analysis where the "outcome" variable of interest is the failure time. Graphically the failure is represented by a "step step" of the line: with each step corresponds the death of a patient. Finally, total MPV/NIV surviva! time was 1131.69 days in MPV/NIV group compared to the 1088.06 days for TIV group (CI 0.30-0.81). No statisticar difference regarding survival in the group treated with MPV/NIV compared to the group treated with TIV has been shown. No correlation was found between survival and any ALS phenotype.

The comparison between the two groups showed asignificant improvement over the time in some respiratory parameters $\left(\mathrm{paO}_{2}\right.$, paco,, , in the group treated with TIV compared MPV/NIV ( $p>0.001, p>0.001$ respectively). The evaluation of the HBQoL showed a higher score profile in patients treated with MPV/NIV compared to TIV ( $p>0.001$ )(fig.3a-b and fig.4).No statistical differences was found in the other parameters evaluated ( albumin,prealbumin,C-reactive protein,a1-glicoprotein, MIP,MEP,SNIP,PCF and ventilation days ) (table 2).

\section{Discussion}

In the two last decades the natural history of neuromuscular diseases (NMDs) changed : it is due particularly to improvements in the diagnosis and treatment of the respiratory complications which can lead rapidly to death ${ }^{30}$. The 55 

1

increasingly widespread application of ventilatory support and assisted coughing as well as the progressive change in the approaching to these patients with early application of NIV and management of multidisciplinary teams has resulted in a considerable improvement in the quality and expenctancy of life for these patients ${ }^{31-34}$. However, there are few studies that have demonstrated the efficacy of MPV associated with other different interfaces in the treatment of ventilatory insufficiency in NMDs ${ }^{14,35-38}$. This is one of the first studies describing the use of MPV in patients with ALS associated with traditional nocturnal NIV and MAC in a population of completely depending patients ventilated until $24 \mathrm{~h}$ per day. No randomized controlled study comparing NIV and TIV is available in medical literature 37,38. However,some evidences from observational studies suggest that Niv should be trailled in all patients except for those with bulbar dysfunction ${ }^{38}$.

NIV has demonstrated to prolong survival in ALS ${ }^{39,40}$. Eariy initiation. of NIY smotid produce a protective role for survival , as well as tracheostomy which showed a lower probability of aeath ${ }^{8,41}$. An interesting study which has evaluated decision-making factors and survival analysis in a jabanese Hospital observed that in a population of 190 people with ALS the use of MV prolorged median survival compared to natural course (75 months for TIV,43 months for NIV,32 months natural course). TIV was the preferred choice in younger patients, in higher progression of the illness and preserved motor functions ${ }^{42}$.

The results obtained in our study confirm the effectiveness of the use of MPV/ NIV until the patient is able to maintain an adequate bulbar function ${ }^{43}$. In patients with severe bulbar impairment, in fact, NIV improves sleep-related symptoms, but it is unlikely to increase survival: therefore, its efficacy is related to the severity of bulbar dysfunction 6,8,9. In a recent review by Heritier Barras et al. on MV in patients with ALS, they claimed that the use of MV 24 hours a day had become a common and well tolerated practice in patients with ALS ${ }^{33}$. On the other hand the use of MPV in the recent years has been increasing in patients with NMDs with promising results ${ }^{44-46}$.To our knowledge our 
Page 10 of 20 1

2

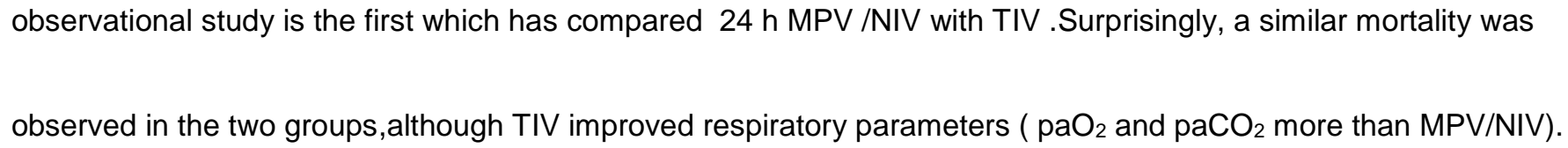

\section{Conclusions}

MPV/NIV has been a safe and effective fashion, to treat patients with $A$.S requiring continuous

ventilatory support.

It has not demonstrated significant differences in survival compared to TIV. Patients treated with MPV/NIV reported a better HRQoL despite lower respiratory values ( ABG,MIP,MEP,SNIP,PCF) over time .Therefore, NIV/MPV should be offered as an alternative to TIV for patients with mantained bulbar timely. It has prolonged free time from diagnosis to death similarly to TIV .These results may be as a starting point for future larger randomized controlled trials.

\section{Acknowledgements}

The authors would like to thank Dr Nicola Pizio,neurologist,Dr Fabrizio Gallo,clinical nutritionist for the help in data collecting and Dr Maura Ferrari-Bravo for statistical analysis. 
2

\section{Conflicts of interest}

The authors declare no financial or other conflicts of interest.

\section{Funding}

This reasearch did not receive any specific grant from funding agencies in the public,commerciai or not-for-profit sectors.

\section{References}

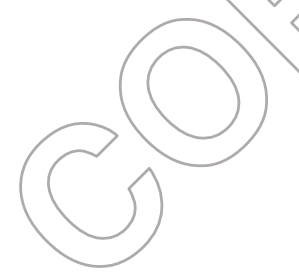

1. Pinto T, Chatwin M, Banf $P$, W Winck JC, Nicolini A. Mouthpiece ventilation and complementary techniques in patients with neuromuscular disease: Arbriếclinical review and update. Chron Resp Dis. 2017;14:187-93

2. Vianello A, Arcerro G, Ori C, Andretta M, Minuzzo M, Bevilacqua M. Trattamento dell'insufficienza respiratoria cronica nelle inaiaitie neuromuscolari in fase avanzata. - Child Development and Disabilities. 2002. p. 49-54.

3. Malik R, Lui A, Lomen-Hoerth C. Amyotrophic lateral sclerosis. Semin Neurol. 2014;34:534-41.

4. Bourke SC, Tomlinson M, Williams TL, Bullock RE, Shaw PJ, Gibson GJ. Effects of non-invasive ventilation on survival and quality of life in patients with amyotrophic lateral sclerosis: a randomised controlled trial. Lancet Neurol 2006;5:140-7

5. Bourke SC, Gibson GJ. Non-invasive ventilation in ALS: current practice and future role. Amyotroph Lateral Scler Motor Neuron Disord 2004; 5: 67-71.

6. Lechtzin N, Scott Y, Busse AM, Clawson LL, Kimball R, Wiener CM. Early use of non-invasive ventilation prolongs survival in subjects with ALS. Amyotroph Lateral Scler 2007; 8: 185-8.

7. Pinto A, Evangelista T, de Carvalho M, Alves MA,Sales-Luis ML. Respiratory assistance with a non-invasive ventilator (BiPAP) in MND/ALS patients: survival rates in a controlled trial. J Neurol Sci 1995; 129(Suppl.): 19-26.

8. Vitacca M, Montini A, Lunetta C, Banfi P, Bertella E, De Mattia E, Lizio A, Volpato E, Lax A, Morini R, Paneroni M; ALS RESPILOM Study Group.Impact of an early respiratory care programme with non-invasive ventilation adaptation in patients with amyotrophic lateral sclerosis. Eur J Neurol. $2018 ; 25: 556-\mathrm{e} 33$. 


\section{Page 12 of 20}

9. Hess DR non invasive ventilation for neuromuscular disease.Clin chest Med 2018;39:437-47

10. Garuti G, Nicolini A, Grecchi B, Lusuardi M, Winck JC, Bach JR. Open circuit mouthpiece ventilation: Concise clinical review. Revista Port de Pneumol. 2014;20:211-8.

11. Bach JR, Alba AS, Saporito LR. Intermittent positive pressure ventilation via the mouth as an alternative to tracheostomy for 257 ventilator users. Chest. $1993 ; 103: 174-82$.

12. Farrero E,Anton A,Egea CJ,Almaraz MJ,Masa JF,Utrabo I et al.Guidelines for the management of respiratory complications in patients with neuromuscular disease.Arch Broconeumol 2013;49:306-13

13. Khirani S, Ramirez A, Delord V, Leroux K, Lofaso F, Hautot S, et al. Evaluation of Ventilators for Miouthpiece Ventilation in Neuromuscular Disease. Respir Care. 2014; 59:1329-37

14. Bédard M-E, McKim DA. Daytime Mouthpiece for Continuous Noninvasive Ventilation in Individuals With Amyotrophic Lateral Sclerosis. Respir Care. 2016; 61:1341-8

15. Gelinas DF, O_Connor P, Miller RG. Quality of life for ventilator-dependent ALS patients and their caregivers. J Neurol Sci 1998; 160: S134-6.

16. Mustfa N, Walsh E, Bryant $\mathrm{V}$, et al. The effect of noninvasive vertiliation on ALS patients and their caregivers. Neurology 2006; 66: 1211-7.

17. Turner MR, Bakker M, Sham P, Shaw CE, Leigh PN, Al-Chaiobi A. The Kingss Database 1999-2000: an analysis of the effect on survival of interventions in amyotrophic ateral sclerosis. Almyotroph Lateral Scler Motor Neuron Disord 2001;2:43..

18. Cazzolli PA, Oppenheimer EA. Home mechanical ventilation for amyotrophic lateral sclerosis: nasal compared to tracheostomy-intermittent positive pressure ventilation. J Neurol Sci 19966; 139: 123-8.

19. Miller RG, Jackson CE, Kasarkis EJ ei al. Practíse Parameter update: the care of the patient with amyotrophic lateral sclerosis: drug, nutritional, and respiratory therapies (an evidence-based review). Neurology 2009; 73: 121826.

20. Brooks BR, Miller RG, Swash M, Munsat TL. Ef Escorial revisited: revised criteria for the diagnosis of amyotrophic lateral sclerosis. Amyotroph Lateral Scler, 2000;1:293-9.

21. Miller MR, Hankinson J, Brusasco V, Burgos F, Casaburi R, Coates A, et al. Standardization of spirometry. Eur Resp. d. 2005,25:319-38

22. Pellegrino R, Viegi G,Brusasco V,vrapo RO,Burgos F,Casaburi R, Coates A et al. Interpretative strategies for lung function tests.Eur Resp J 2005;26:948-68

23. ATS/ERS Statement on Respiratory Muscle testing.Am J Resp Crit Care Med 2002;166:528-621

24. Evans JA, Whitelaw WA. The assessment of maximal respiratory mouth pressure in adults. Resp Care 2009;54:1348-59

25. Capozzo R, Quaranta VN, Pellegrini F, Fontana A, Copetti M, Carratù P, et al. Sniff nasal inspiratory pressure as a prognostic factor of tracheostomy or death in amyotrophic lateral sclerosis. J Neurol. 2015;262:593-603.

26. Nicolini A, Parrinello L, Ferrari-Bravo M, Barlascini C, Banfi P. Diurnal Mouthpiece Ventilation and Nocturnal 
Page 13 of 20

Noninvasive Ventilation vs Invasive Mechanical Ventilation in Patients With Amyotrophic Lateral Sclerosis. Chest. 2016;abstract

27. Majani G, Callegari S, Pierobon A, et al. A new instrument in Quality of Life assessment.The Satisfaction Profile (SAT-P). Int J Ment Health. 1999;28: 77-82

28. Devoto G,Gallo F,Marchello C,Racchi O,Garbarini R,Bonassi S, et al.Prealbumin serum concentration as a useful tool in the assessment of malnutrition in hospitalized patients.Clin Chem 2006;52:2281-5

29. Bach JR, Goncalves MR, Hon A, Ishikawa Y, De Vito EL, Prado F, et al Changing trends in the management of end-stage neuromuscular respiratory muscle failure: recommendations of an international consensus. Am J Phys Med Rehabil. 2013;92:267-77.

30. Ferrero E,Anton A,Egea CJ,Almaraz MJ,Masa JF,Utrabo I et al. Guidelines for the rnanagement of respiratory complications in patients with neuromuscular diseases.Arch Broconeumol 2013;49;306-13

31. Simonds AK. Recent advances in respiratory care for neuromuschilar diseases.Chest 2006;130:1879-86

32. Farrero E,Prats E,povedano M,Martinez-matos JA,Escarrabill J.Survival in amyotrophic lateral sclerosis with home mechanical ventilation : the impact of systematic respiratory assessment and bulbar involvement.Chest $2005 ; 127: 2132-8$

33. Barras ACH, Adler D, Ferfoglia RI, Ricou B, Gasche Y, Leuchter I, et al Istracheostomy still an option in amyotrophic lateral sclerosis? Reflections of a multidisciplinary workgroup. Swiss Medical Weekly. 2013; 143:w13830

34. Sancho J.Martinez D,Bures E,Diaz JL,Ponz,A,Servera E.Bulibarimpairment score and survival of stable amytrophic lateral sclerosis patients after non inabsive vertilation initiation.ERJ Open Res 2018;4:00159-2017

35. Nardi J, Leroux K, Orlikowski D, Prigent H, Lofaso F. Home monitoring of daytime mouthpiece ventilation effectiveness in patients with neuromuscular disease. Chron Respir Dis. 2016;13:67-74

36. Bach JR,Alba AS,Saporito LR. Intermittent positivepressure ventilation via the mouth as an alternative to tracheostomy for 257 ventíäor lisers. Ches: 1993;103:174-82

37. Radunovic A,Annane D, Rafio MK,Brassington R,Mustfa N.mechanical ventilation for amyotrophic lateral sclerosis/motor neuron disease.Cochrane Database System Rev 2017;10:CD004427DOI

38. Luo F,Annane D, O lik.owski D,He L,Yang M,Zhou M,liu GJ.Invasive versus non-invasive ventilation for acute respiratory failure in neuromuscular disease and chest wall disorders ( Review ).Cochrane Database System Rev 2017; 12:CD008380

39. Burkhardt C,Neuwirth C,Sommacal A,Andersen PM,Weber M.Is survival improved by the use of NIV and PEG in amyotrophic lateral sclerosis (ALS)?A post-mortem study of 80 ALS patients .PLOS One 2017;12::1-12

40. Vrijsen B,Testtelmans D,Belge C,Robberecht W,Van Damme P,Buyse B.Non-invasive ventilation in amyotrophic lateral sclerosis.Amyoth Lat Scler Front Deg 2013;14:85-95

41. Bertella E,Banfi P,Paneroni M,Grilli S,Bianchi L,Volpato E,Vitacca M.Early initiation of night-time NIV in an outpatient setting:a randomized non-inferiority study in ALS patients.Eur J Phys Rehab Med 2017;53:892-9

42 Kimura F.Tracheostomy and invasive mechanical ventilationin amyotrophic lateral sclerosis :decision making factors and survival.Clin Neurol 2016;56:241-7

43. Sanjuan-Lopez P, Valino-Lopez P,Ricoy-Gabaldon J,Verea-Hernando H.Amyotrophic lateral sclerosis : Impact of pulmonary follow-up and mechanical ventilation on survival.A study on 114 cases. Arch Bronconeumol 2014;50;509-13 
Page 14 of 20

44. Bach JR,Mehta AD.Respiratory muscle aids to avert respiratory failure and tracheostomy : a new patient management paradigm.J Neurorestoratol 2014;2:25

45. Villanova ,Brancalion B,Mehta AD.Duchenne muscular dystrophy . life prolongation by noninvasive ventilatory support Am J Phys Med Rehabil 2014;93:595-9

46. Benditt JO,Boitano LJ.Pulmonary issues in patients with chronic neuromuscular disease.Am J Respir Crit Care Med 2013;187:1046-55

Table 1 Criteria to start day time non invasive ventilation

- Persistent diurnal hypercarbia $>50 \mathrm{mmHg}$ and or when $\mathrm{SpO}_{2}<92 \%$ while awake

- Daytime dyspnoea

- Non invasive ventilation use $>12 \mathrm{~h} /$ day

Table 2a Characteristics of the patients at baseline

Parameter

MPV group

TIV group

p-value

age

$67,6 \pm 4,6$

BMI

$24,9 \pm 4,7$

$71,6 \pm 3,0$

0,3432

prealbumin

$16,5 \pm 3,0$

$23,6 \pm 2,6$

0,3298

albumin

$3771 \pm 304$

$18,8 \pm 1,9$

0,0886

$\alpha 1$ acid glic

$88,4 \pm 19,7$

$3.876 \pm 236$

0,4414

C-RP

$0,7 \pm 0,2$

$90,3 \pm 15,6$

0,8239

FVC

$84,8 \pm 9,2$

$0,7 \pm 0,2$

0,9448

FEV $_{1}$

MIP

$81,3 \pm 10,8$

$85,9 \pm 9,2$

0,8114

$69,9 \pm 10,5$

$77,6 \pm 10,7$

0,4902

$66,4 \pm 7,1$

$69,8 \pm 7,1$

0,9602

MEP

SNIP

$67,1 \pm 8,0$

$65,4 \pm 8,1$

0,7385

PCF

$370,0 \pm 32,9$

$64,1 \pm 5,8$

0,3219

$95,7 \pm 1,1$

$355,6 \pm 53,8$

0,5316

$\mathrm{satO}_{2}$

$79,3 \pm 3,4$

$95,9 \pm 1,2$

0,6932

$\mathrm{paO}_{2}$

$38,6 \pm 2,2$

$83,0 \pm 4,4$

0,2059

$\mathrm{paCO}_{2}$

$7,4 \pm 0,0$

$39,3 \pm 2,6$

0,4999

$\mathrm{Ph}$

$10,1 \pm 2,8$

$7,4 \pm 0,0$

0,0940

$\mathrm{AHI}$

$16,1 \pm 5,4$

$9,6 \pm 4,3$

0,7630

ODI

$72,8 \pm 7,7$

$15,6 \pm 3,1$

0,7732

Sat-P

$71,9 \pm 7,6$

0,8066 
1 MPV .mouthpiece + nocturnal non-invasive ventilation group

2 TIV tracheostomy invasive ventilation group

3 ALS amiotrphyc lateral sclerosis

4

BMI Body mass index a1-glic alfa-1 acid glycoprotein C-RP C-reactive protein FVC Forced vital capacity FEV 1 Forced expiratory pressure at first second MIP Maximal inspiratory pressure MEP Maximal expiratory pressure SNIP Sniff nasal inspiratory pressure PCF Peak cough flow satO $\mathrm{O}_{2}$ oxygen saturation $\mathrm{paO}_{2}$ Oxygen arterial pressure $\mathrm{paCO}_{2}$ carbon dyoxide arterial pressure AHI Apnea-hypopnea index ODI Oxygen desaturation index Sat-P Satisfaction Profile

Table $\mathbf{2 b}$ ALS phenotypes in the two groups

\begin{tabular}{|c|c|c|}
\hline Phenotype & MPV group & TIV group \\
\hline Bulbar & 0 & \\
\hline Classic & 8 & \\
\hline Flail arm & 2 & \\
\hline Flail leg & 1 & \\
\hline Pure lower motor neuron & 2 & \\
\hline Pyramidal & 3 & \\
\hline
\end{tabular}

Table 3 Laboratory, respiratory and HRQoL parameters over time

\begin{tabular}{|c|c|c|c|c|c|c|c|}
\hline \multirow[t]{2}{*}{ Parameter } & \multicolumn{2}{|l|}{ TO } & \multicolumn{2}{|l|}{ F1 } & \multicolumn{2}{|l|}{$\mathrm{T} 2$} & \multirow[t]{2}{*}{$\mathrm{p}$-value } \\
\hline & MPV & $N V \cap>$ & MPV_ & TIV & MPV & TIV & \\
\hline Prealbumin & $16.5 \pm 3.0$ & $18.8 \pm 1.9$ & $14.7 \pm 2.4$ & $15.0 \pm 1.3$ & $13.1 \pm 1.8$ & $12.2 \pm 0.4$ & 0.08 \\
\hline Albumin & $3.771 \pm 304$ & $3.876 \pm 236$ & $3.542 \pm 277$ & $3.425 \pm 181$ & $3.465 \pm \pm 242$ & $3.415 \pm 121$ & 0.23 \\
\hline C-RP & $0.7 \pm 0.2$ & $0.7 \pm 0.2$ & $0.6 \pm 0.2$ & $0.7 \pm 0.4$ & $0.6 \pm 0.2$ & $0.8 \pm 0.2$ & 0.26 \\
\hline MIP & $69.9 \pm 10.5$ & $69.8 \pm 7.1$ & $49.9 \pm 7.0$ & $46.5 \pm 4.7$ & $34.0 \pm 5.7$ & $33.4 \pm 5.3$ & 0.31 \\
\hline MEP & $66.4 \pm 7.1$ & $65.4 \pm 8.1$ & $49.9 \pm 5.3$ & $45.5 \pm 7.1$ & $37.1 \pm 4.2$ & $36.2 \pm 4.0$ & 0.12 \\
\hline SNIP & $67.1 \pm 8.0$ & $64.1 \pm 5.8$ & $48.9 \pm 5.0$ & $39.9 \pm 9.0$ & $34.5 \pm 4.2$ & $30.9 \pm 5.2$ & 0.06 \\
\hline PCF & $370.0 \pm 32.9$ & $355.6 \pm 53.8$ & $270.1 \pm 21.0$ & $257.5 \pm 24.8$ & $193.1 \pm 19.7$ & $186.3 \pm 23.5$ & 0.14 \\
\hline $\mathrm{paO}_{2}$ & $79.3 \pm 3.4$ & $83.0 \pm 4.4$ & $63.9 \pm 5.4$ & $59.3 \pm 4.9$ & $51.8 \pm 3.0$ & $61.3 \pm 2.5$ & 0.001 \\
\hline $\mathrm{paCO}_{2}$ & $38.6 \pm 2.2$ & $39.3 \pm 2.6$ & $44.6 \pm 6.2$ & $43.9 \pm 3.9$ & $54.3 \pm 0.5$ & $42.0 \pm 0.8$ & 0.001 \\
\hline SAT-P & $72.8 \pm 7.7$ & $71.9 \pm 7.6$ & $55.3 \pm 10.0$ & $53.7 \pm 7.2$ & $42.9 \pm 5.1$ & $30.7 \pm 1.4$ & 0.001 \\
\hline $\begin{array}{l}\text { Time } \\
\text { ventilation } \\
\text { (days) }\end{array}$ & & & & & 617.56 & 782.69 & 0.09 \\
\hline $\begin{array}{l}\text { Survival } \\
\text { days }\end{array}$ & & & & & 1131.63 & 1088.06 & 0.27 \\
\hline
\end{tabular}

T0 Disease diagnosis phase T1 Starting mechanical ventilation T2 Last three months MPV : mouthpiece non- invasive ventilation group TIV tracheostomy invasive ventilation group 
Page 16 of 20

C-RP C reactive protein MIP maximal inspiratory pressure MEP maximal expiratory pressure SNIP PCF satO2 : oxygen saturation paO2 paCO2 SAT-P satisfaction Profile

HRQoL Health related quality of life

5

6

7

Legends

Table 1 Criteria to start day time non invasive ventilation

Table 2a Characteristics of the patients at baseline

Table 2b ALS phenotypes in the two groups

Figure 1 Study flow chart

Figure 2 Survival of patients in Kaplan-Meier model.Blue,patients treated with tracheostomy invasive ventilation 22

25

(TIV);red,patients treated with diurnal mouthpiece ventilation and nocturnal non invasive ventilation (MPV)

Figure 3a-3b Trend over time of $\mathrm{PaO}_{2}$ and $\mathrm{PaCO}_{2}$ in the three examination phases (1.diagnosis phase; 2.start of mechanical ventilation phase;3. last three months of life) in the two groups

Figure 4 Trend over time of Sat-P in the three examination phases 
Page 17 of 20

1

2

3

4

5

6

7

8

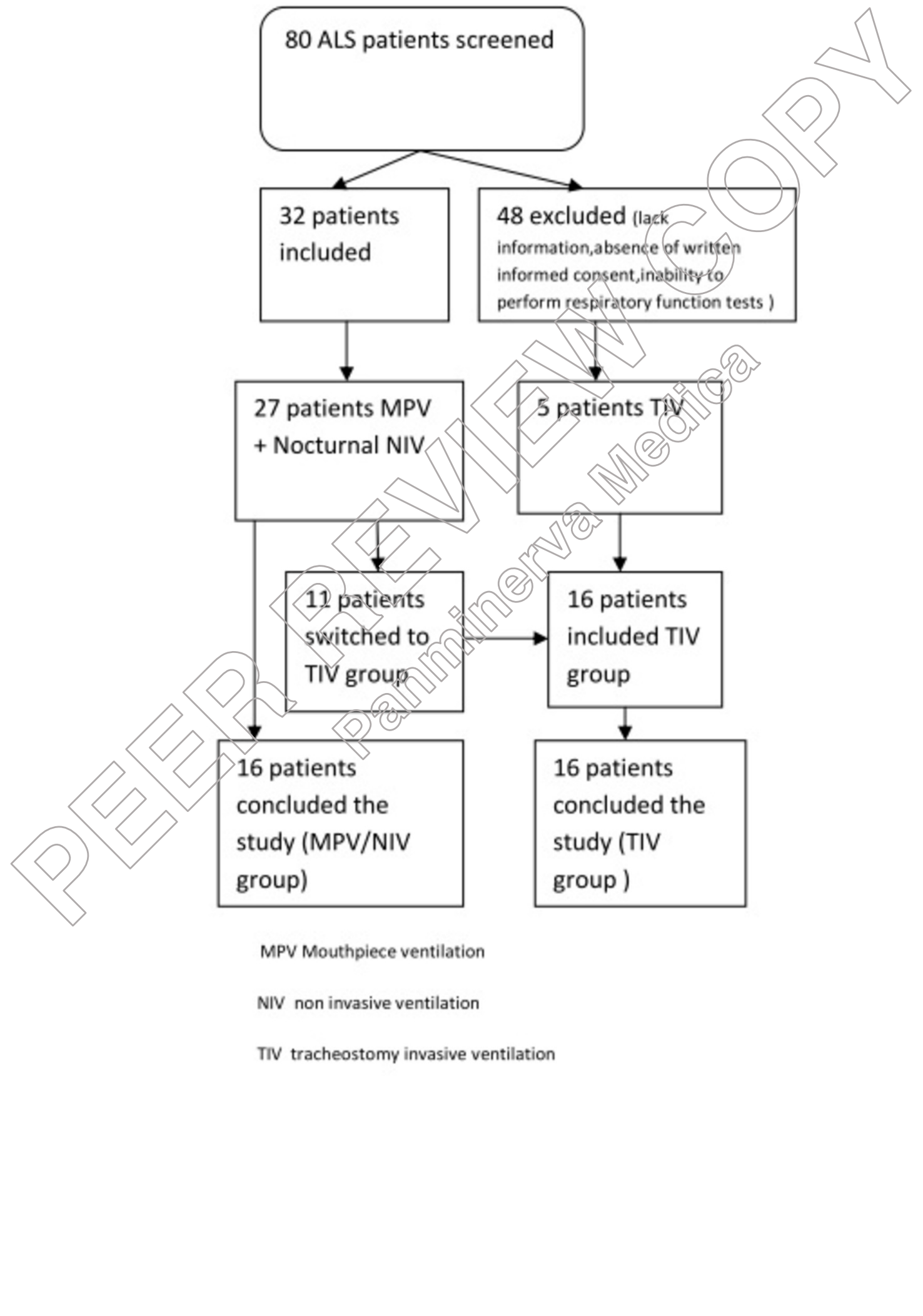


Page 18 of 20

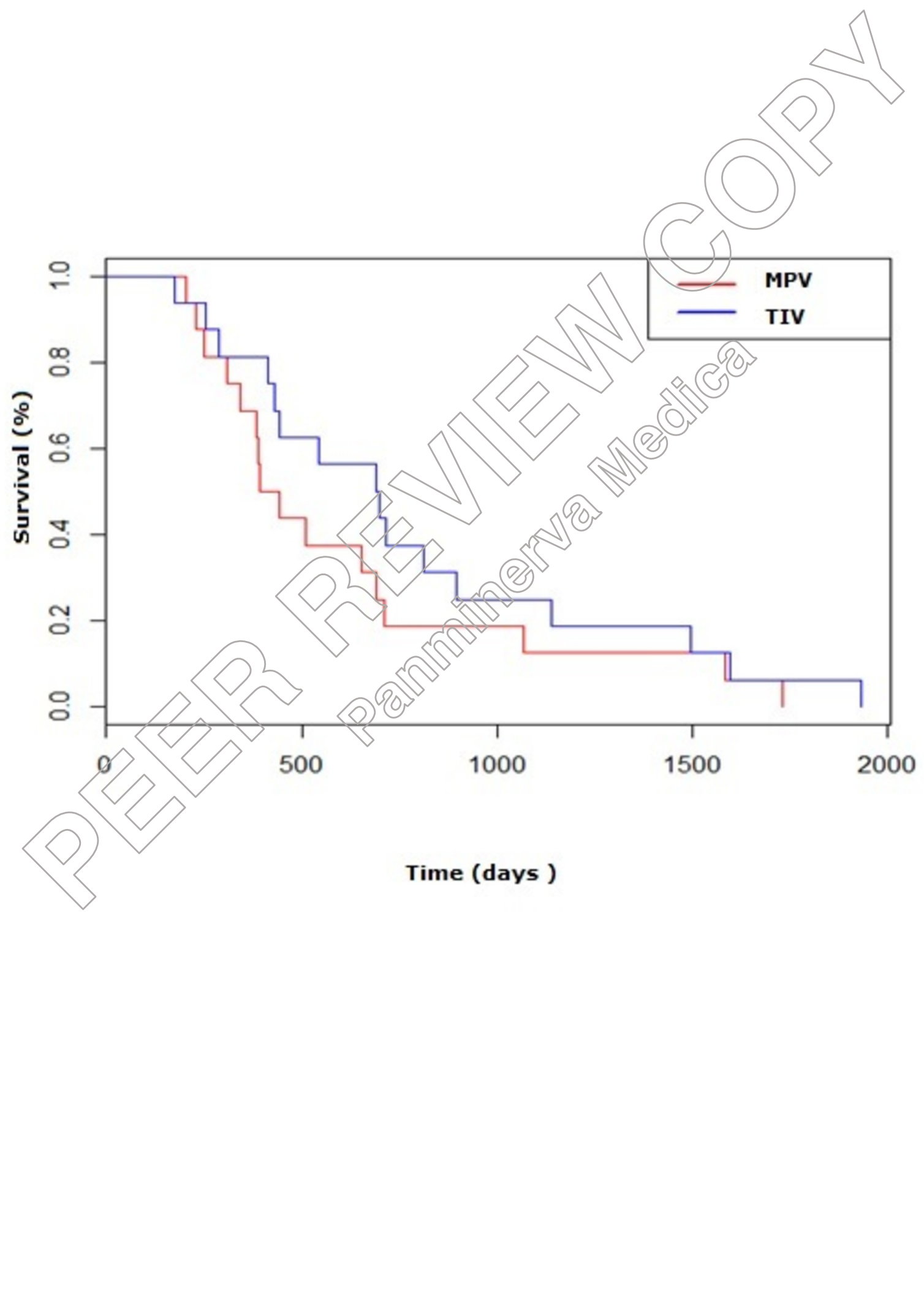


Page 19 of 20

1
2
3
4
5
6
7
8
9
10
11
12
13
14
15
16
17
18
19
20
21
22
23
24
25
26
27
28
29
30
31
32
33
34
35
36
37
38
39
40
41
42
43
44
45
46
47
48
49
50
51
52
53
54
55
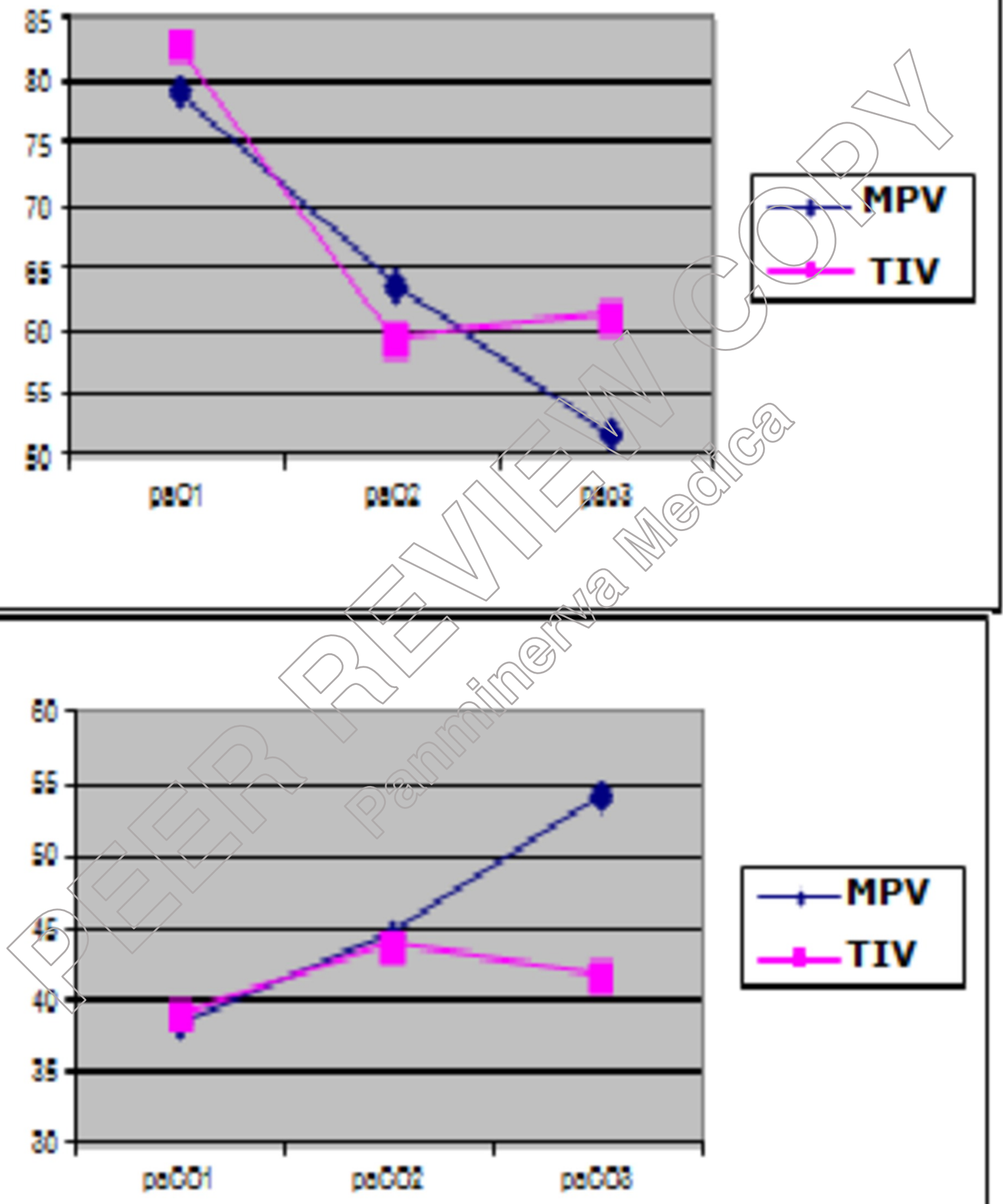
Page 20 of 20

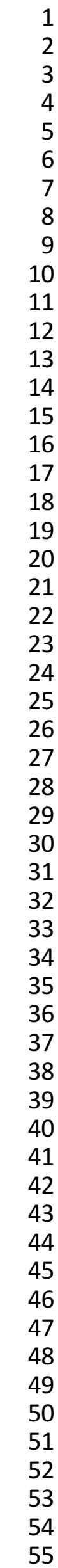

